\title{
Evaluation of Handgun and Broadcast Systems for Spray Deposition in Greenhouse Poinsettia Canopies
}

\author{
R. C. Derksen，C. M. Ranger，L. A. Cañas，J. C. Locke，H. Zhu，C. R. Krause
}

\begin{abstract}
Handgun applicators are popular, general-purpose greenhouse sprayers. However, there are few recommendations on how to use them to treat plant benches. Handgun applications made from one side can result in significant differences in deposits between the side of the plant facing the spray stream and the opposite side. Broadcast spraying over the top of the canopy may improve spray distribution across the canopy. The objective of this research was to determine differences in performance between different sprayers used to treat mature poinsettias and differences in the fate of the spray within the canopy with the aim to determine which techniques produced the highest spray retention on the abaxial leaf surface. A benchtop trial was conducted using a mature poinsettia canopy in a greenhouse. Sprayer treatments were used to apply tank mixes of pesticides and fluorescent tracer. Nylon screen targets were secured to the abaxial surfaces of leaves in the upper and lower parts of the canopy. Benchtop trials revealed significant differences between the amount of spray found on the upper and lower canopy target areas. Handgun nozzle pressure was a more significant factor in depositing material on the abaxial surfaces of leaves than changing application rate. A TwinJet boom system using dual-orifice nozzles did not treat abaxial surfaces differently from the handgun applications. The air-assist treatment with flat-fan nozzles produced the highest mean deposits on abaxial surfaces in the lower canopy area, but overall there were no statistical differences in lower canopy deposits between treatments. These results demonstrate the difficulty that ornamental producers have in targeting pesticide placement on abaxial leaf surfaces deeper in the canopy. The variability in spray deposits observed on foliage demonstrates the potential for significant variability in pest management.
\end{abstract}

Keywords. Air-assisted sprayers, Droplet, Greenhouse, Poinsettia, Spray deposition, Sprayers.

$\mathrm{P}$ esticides continue to play an important role in pest management programs for greenhouse ornamentals as growers try to provide the marketplace with healthy and cosmetically appealing products. In the 2007 reporting year, consumers purchased potted flowering plants for indoor or patio use with a value of $\$ 661$ million, $6 \%$ more value than in 2006. Poinsettias were the most popular potted flower in this category, with production of 47.5 million pots representing \$181 million in value in 2006 (USDA, 2008).

Greenhouse structures pose unique pest management challenges that limit application equipment choices. Handheld applicators are frequently used to apply pesticides in greenhouses because of limitations of the structure or operating space. Hand-held applicators also provide growers with

Submitted for review in August 2009 as manuscript number PM 8181; approved for publication by the Power \& Machinery Division of ASABE in January 2010. Presented at the 2009 ASABE Annual Meeting as Paper No. 097453 .

The authors are Richard Charles Derksen, ASABE Member Engineer, Agricultural Engineer, and Christopher M. Ranger, Research Entomologist, USDA-ARS Application Technology Research Unit (ATRU), Wooster, Ohio; Luis A. Cañas, Associate Professor and Entomologist, Department of Entomology, The Ohio State University, Wooster, Ohio; James C. Locke, Research Plant Pathologist, Heping Zhu, ASABE Member Engineer, Agricultural Engineer, and Charles R. Krause, Research Leader, USDA-ARS ATRU, Wooster, Ohio. Corresponding author: Richard Charles Derksen, USDA-ARS Application Technology Research Unit (ATRU), Agricultural Engineering Building, 1680 Madison Avenue, Wooster, OH 44691; phone: 330-263- 3869; fax: 330-263-3869; e-mail: rich.derksen@ars.usda.gov. flexibility to spot-treat problem areas or to more easily work around different crops being grown in close proximity to each other that many not require the same treatment.

Derksen and Sanderson (1996) found that in a mature poinsettia canopy, a hand-held, low-volume, air-assist electrostatic sprayer produced significantly higher deposits on the underside of leaves at the bottom of the canopy compared to a high-volume handgun treatment using only $1 / 25$ the spray volume and treating the area three times more quickly. However, the authors also reported that the treatment effects were not consistent on all leaf surfaces at different canopy elevations. Ebert et al. (2003) showed in efficacy trials of two-spotted spider mite (Tetranychus urticae Koch), western flower thrips (Frankliniella occidentalis (Pergande)), and soybean aphid (Aphis glycines Matsumura) that the three different forms of handgun application equipment (highvolume, coldfogger, and air-assist electrostatic) had no consistent effect on efficacy when used to apply the same volume of spray. However, through bioassay evaluations, Ebert et al. (2003) also provided evidence that spray quality, while not evaluated as an independent variable, may be a significant factor affecting efficacy.

Growers also find that it is easy to visualize spray coverage, and thus the treated areas, more easily with a highvolume, hand-held application. Unfortunately, hand-held applicators are usually directed at one side of a canopy only, and such use can result in wide variations in deposit patterns. Derksen et al. (2008) found that spray canopy position was a significant factor in the amount of spray found on foliar and artificial targets. There was a $4 \times$ difference in the amount of material found between the top of the canopy and the lower 
part of the canopy near the pot. There was also a $10 \times$ difference in the amount of material found on the back side of the plant compared to the front side facing the nozzle. Derksen et al. (2008) also reported there were few differences in spray deposit between treatments of different spray volumes. The high-volume application produced the highest deposits on artificial targets across all spray qualities. However, the deposit measurements were not made to distinguish between abaxial and adaxial leaf surfaces.

While single-orifice, hand-held applicator sprays rely on the operator to provide a uniform application, over-thecanopy boom sprayer or broadcast applications, such as those commonly used in field crops, can help ensure a more uniform spray deposition across the application width. Knewitz et al. (2003) reported that a hand-held boom using cone nozzles provided more uniform spray distribution in an ornamental canopy than a single-nozzle handgun. Langenakens et al. (2002) also reported that boom or broadcast applications provided more uniform spray distribution than a handgun application to greenhouse plants on the floor. Using vertical spray booms to treat greenhouse pepper and tomato plants, Nuyttens et al. (2004) reported that spray distribution from $80^{\circ}$ flat-fan nozzles was better for a nozzle spacing of $35 \mathrm{~cm}$ than for $50 \mathrm{~cm}$. Nuyttens et al. (2004) also reported that optimum nozzle-to-target distance was $30 \mathrm{~cm}$ for $80^{\circ}$ flat-fan nozzles with a spacing of $35 \mathrm{~cm}$.

One of the problems that over-the-canopy applications need to overcome is canopy penetration and coverage on the abaxial surfaces of leaves. Changes in the angle that spray is presented to a canopy and air-assistance are two means that have been explored to increase canopy penetration with varying degrees of success. Zhu et al. (2002) demonstrated that inclining a single-fan spray pattern $15^{\circ}$ forward did not improve spray penetration in a peanut canopy. Zhu et al. (2004) found that a twin-fan nozzle $\left(30^{\circ}\right.$ forward and back from vertical) produced better spray penetration into a peanut canopy than a conventional single-orifice flat-fan nozzle. Ozkan et al. (2006) found that discharge from a twin-fan (TeeJet TJ60) nozzle reduced spray deposits in a relatively tall, dense, narrow-row, soybean canopy. Derksen et al. (2007) reported that twin-fan nozzles with spray discharge $30^{\circ}$ forward and back from vertical produced similar amounts of foliar spray deposits in mature bell pepper canopies compared to airassisted delivery and low-drift nozzle treatments, but lower spray coverage on the abaxial leaf surfaces.

Air-assisted spraying is used to help deliver spray through greater distances and to cause foliage to deflect, which increases the chances of deposition on more of the foliage surface. Several studies examining row-crop canopy spray deposits have demonstrated that, at the same carrier rate, airassisted delivery improves canopy penetration and deposition compared to conventional delivery through non-airassisted techniques (Derksen et al., 2001; Mueller et al., 2002; Piché et al., 2000; Womac et al., 1992). However, May (1991) reported that spray retention results could vary depending on the design of the air-assist boom sprayer making the application. Fluorescent dye spray coverage studies conducted by Derksen et al. (2007) found that air-assisted delivery produced greater spray coverage on the abaxial surfaces of bell pepper leaves than non-air-assisted delivery using either twin-fan or air induction nozzles.

Targeting the abaxial surfaces of leaves is important for the control of many insect and disease problems in many or- namental crops. The objective of this research was to determine differences in performance between different sprayers used to treat mature poinsettias and differences in the fate of the spray within the canopy with the aim to determine which techniques produced the highest spray retention on the abaxial leaf surfaces.

\section{Materials ANd Methods \\ Experimental Plot}

Poinsettia cuttings (cv. Sonora Jingle) rooted in Oasis strips were received from Raker \& Sons (Litchfield, Mich.) on 22 September 2006. The cuttings were stuck in $15 \mathrm{~cm}$ azalea pots containing Sunshine Mix (Sun Gro Horticulture, Bellevue, Wash.) in the greenhouse facility of the Toledo Botanical Garden on 26 September. The plants were maintained under "long days" with supplemental night break (10:00 p.m. to 2:00 a.m.) lighting to keep the plants vegetative. Plants were pinched to force branching on 26 October, and "long day" conditions were discontinued on 13 December. Figure 1 illustrates the layout for each replicate of each treatment. The positions of the target plants were constant for each equipment pass. Poinsettias were spaced $27 \mathrm{~cm}$ on center on the bench. The target plants were replaced between each test application, and the border plants remained in place.

Monofilament nylon screen targets (Filter Fabrics, Inc., Goshen, Ind.) were used to simulate leaves to collect foliar spray deposits within the poinsettia canopy. Each screen size was $3.8 \mathrm{~cm} \times 3.8 \mathrm{~cm}$. The screen had a nominal porosity of approximately $56 \%$ and fiber frontal area percentage of $44 \%$ (Fox et al., 2004). Individual screens were attached to the abaxial surfaces of two leaves from each of the upper and lower canopy elevations using double-sided tape prior to spray treatment (fig. 2), resulting in four total targets per plant. Target leaves were chosen at random at each elevation but were selected to be larger than the targets.

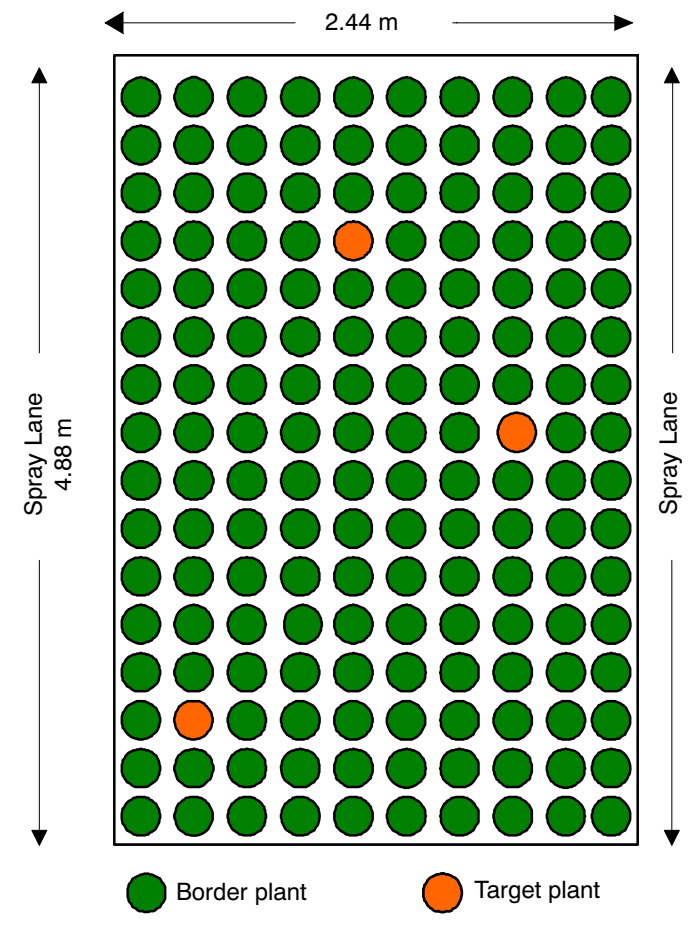

Figure 1. Experimental layout for each replicate. 


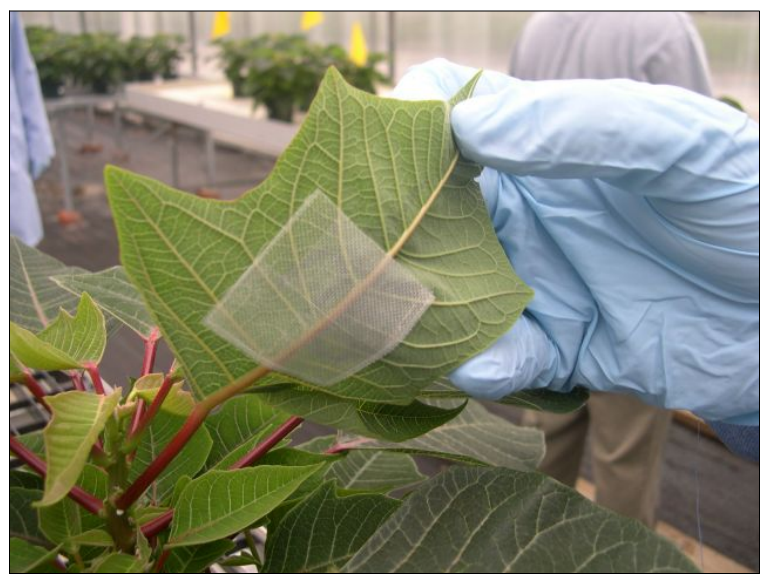

Figure 2. Plant with screen targets on abaxial surface of leaf.

\section{TreatMents}

The operating parameters and the atomization characteristics of the four treatments used in this study are described in table 1. Each treatment was replicated five times, with three plants containing unused targets being randomly placed on the benchtop for each replicate. The order of the applications was not replicated, and all replicates for each treatment were completed before changing treatments. All treatments were operated at travel speeds to provide the desired application rate for the nozzle output. A spray mixture containing water and Brilliant Sulfaflavine (BSF) (MP Biomedicals, Inc., Aurora, Ohio) at a concentration of $3 \mathrm{~g} \mathrm{~L}^{-1}$ was used for the trials for all treatments. Figure 3 illustrates use of the Dramm Hydra handgun (model MS40-TG, $1.0 \mathrm{~mm}$ tip, Dramm Corp., Manitowoc, Wisc.) used in these trials.

Table 1. Spray equipment parameters.

\begin{tabular}{lccc}
\hline & $\begin{array}{c}\text { Spray Liquid } \\
\text { Pressure } \\
(\mathrm{kPa})\end{array}$ & $\begin{array}{c}\text { Nozzle } \\
\text { Output } \\
\left(\mathrm{L} \mathrm{min}^{-1}\right)\end{array}$ & $\begin{array}{c}\text { Application } \\
\text { Rate } \\
\left(\mathrm{L} \mathrm{ha}^{-1}\right)\end{array}$ \\
\hline Dreatment & 930 & 1.70 & 467 \\
Dramm Hydra (1.0) & 930 & 1.70 & 934 \\
TwinJet boom (TJ60-11002VS) & 930 & $5.19[\mathrm{a}]$ & 934 \\
Air-assist (XR11003) & 758 & $6.51^{\mathrm{b}]}$ & 934 \\
Dramm Hydra (1.0) & 3,583 & 3.41 & 934 \\
\hline
\end{tabular}

[a] Total output from four nozzles.

[b] Total output from five nozzles.

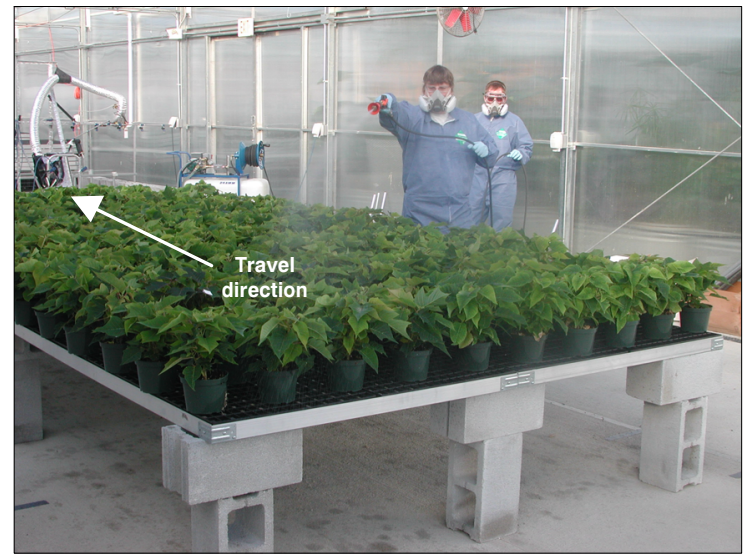

Figure 3. Dramm Hydra trigger gun, model MS40-TG (1.0 mm tip).

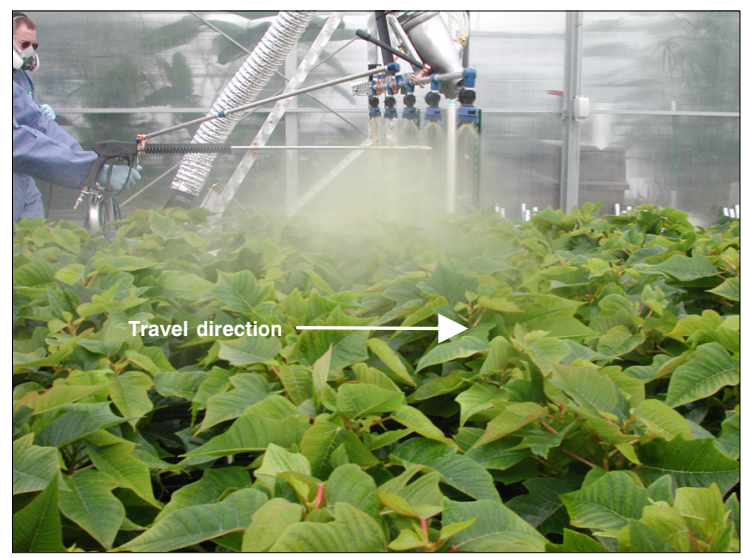

Figure 4. Boom sprayer with TwinJet nozzles.

The four-nozzle boom sprayer arrangement (TwinJet boom) with TJ60-11002VS nozzles (Spraying Systems Co., Wheaton, Ill.) is shown in figure 4 . The nozzle tips were positioned $30 \mathrm{~cm}$ over the top of the canopy. The boom was mounted to a hand cart that was pushed down the spray lane on either side of the test bench.

The air-assist, five-port nozzle is pictured in figure 5 . The five-port nozzle consisted of an air manifold with five ports (Montana Industrials, Dal Negro, Brazil; distributed by Pickin' Patch, Inc., Plymouth, Ind.) and five nozzles. The internal geometric construction of the five-port air manifold is described by Zhu et al. (2006). The manifold was cast with five ports at $15^{\circ}$ radial separation, each with an inside diameter of $3.6 \mathrm{~cm}$. The liquid discharger was a modified flat tip (XR11003, Spraying Systems Co., Wheaton, Ill.) and was mounted at the centerline of each port of the five-port air manifold. The air-assist, five-port nozzle was also mounted on a hand cart that was pushed down the spray lane on either side of the treatment area. The air for the air-assist nozzle was provided by a leaf blower/vacuum (model BV4000, Black \& Decker, Towson, Md.) mounted on the handcart. The fiveport manifold was operated at $30^{\circ}$ forward of vertical with the center of the manifold $35.6 \mathrm{~cm}$ above the canopy.

Air velocity measurements of the modified five-port spray nozzle were made using an air velocity meter (model 8386A VelociCalc, TSI, Shoreview, Minn.). The air velocity at the five outlets was measured directly at each nozzle outlet and centered within the air jets at a distance of $35.6 \mathrm{~cm}$ below

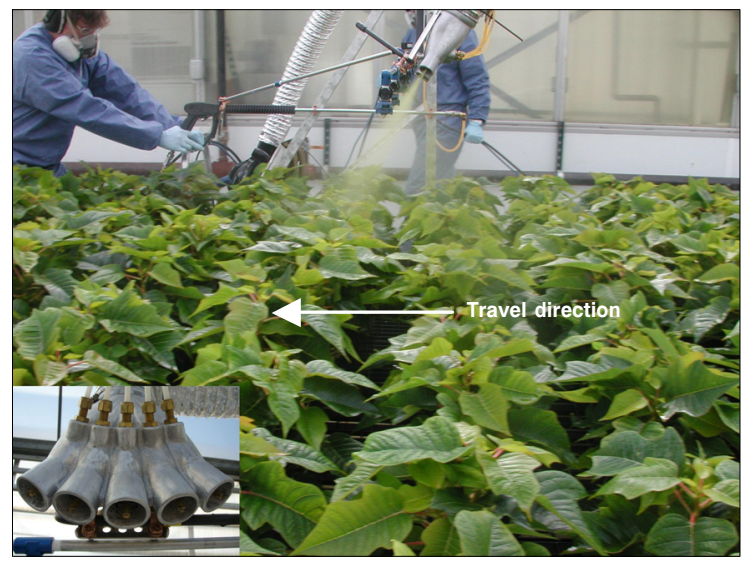

Figure 5. Five-port, air-assist sprayer with XR11003 nozzles. 
each nozzle. The air velocity measurements that were made directly at the nozzle outlets were offset from the spray tips, which were mounted in the center of the spray nozzles and interfered with measurements directly at the outlet.

The equipment operator practiced making applications before turning on the sprayer before each application. A second staff member called out the elapsed spray time to help the applicator keep his pace. The other spray team member also called out the elapsed time during the actual treatment. The Dramm Hydra handgun was moved across the test area in a zig-zag pattern over the canopy. The operator directed the spray 2.4 to $3.7 \mathrm{~m}$ in front of the nozzle as the spray pattern was moved across the plant canopy. The total amount of spray applied by the handgun treatment was controlled by monitoring the application time. The $935 \mathrm{~L} \mathrm{ha}^{-1}$ handgun treatment shown in table 1 was applied in twice the time as the $467 \mathrm{~L}$ $\mathrm{ha}^{-1}$ treatment while using the same equipment settings. While making the slower, higher-volume application, the applicator swept the handgun spray move frequently over the bench.

The TwinJet boom and air-assist treatments were mounted on a four-wheeled handcart that could be pushed or pulled down the aisle on either side of the treatment area. Each of these treatments could only treat half of the test bench in a single pass. Both of these treatments were operated on each side of the treatment area to provide application over the entire treatment area. The TwinJet boom and air-assist treatments were pushed or pulled to ensure the same direction of treatment over the entire treatment area.

\section{Droplet Sizing and Velocity Measurement}

Droplet size distributions and droplet velocity for test nozzles were determined using a particle/droplet laser image analysis system (VisiSizer and PIV, Oxford Lasers, Ltd., Oxfordshire, U.K.) described by Güler et al. (2007). During the tests, the laser image analysis system setting was lens option 3 at magnification setting 1 . At this setting, the system could measure droplets from 42.8 to $1023.7 \mu \mathrm{m}$. At least 10,000 droplets were counted for the size measurements. Twenty pairs of images were sampled for velocity measurements. Cross-correlation, window velocity, interpolate outliers, and median velocity filters were applied to the image velocity measurements. Droplet samples were taken $50 \mathrm{~cm}$ below the nozzle orifice for the TwinJet boom (TJ60-11002VS) and air-assist (XR11003) treatments and across centerline along the long axis of the spray pattern by scanning within $30 \mathrm{~cm}$ on either side of the centerline of the spray patterns. Droplet samples for the Dramm Hydra (1.0) treatments were made within $10 \mathrm{~cm}$ of the spray pattern centerline. The measurement for each condition was replicated three times. Because the Dramm Hydra treatments were directed to treat at much great distances from the nozzle than the broadcast TwinJet boom or air-assist treatments, the Dramm Hydra treatment droplet spectra were also sampled at 119 and $115 \mathrm{~cm}$ from the nozzle for the sizing and velocity measurements, respectively. These distances were the maximum possible sampling distances for the existing equipment configuration. Atomization characteristics of the air-assist XR11003 nozzle were measured with the center nozzle only connected to water and air blowing through the unit.

\section{BSF Tracer Extraction}

Following treatment, target plants from the locations identified in figure 1 were removed from the treatment area and replaced with three untreated plants and new targets. After a drying time of approximately $10 \mathrm{~min}$, the screens from the treated plants were removed. The two screens from each elevation on an individual plant were collected and placed in $125 \mathrm{~mL}$ glass bottles.

Spray deposits were extracted from the targets by rinsing with $30 \mathrm{~mL}$ of purified water (prepared with Mega-Pure System, model MP-12A, Barnstead International, Dubuque, Iowa). A $4 \mathrm{~mL}$ sample rinsate solution was then placed in a cuvette for determination of peak fluorescent intensity with a luminescence spectrometer (model LS 50B, Perkin-Elmer, Ltd., Beaconsfield, U.K.) at an excitation wavelength of $460 \mathrm{~nm}$. If a sample concentration fell above the calibration range, it was further diluted and measured again. Quantification of dye deposition was achieved using a standard concentration curve prepared with serially diluted samples of known concentration. The mass of tracer found on the targets was converted to spray volume using the concentration of tracer in the tank mix because not all treatments applied the same rate of tank mix.

\section{Statistical Analyses}

Potential outliers in the deposition data for each BSF delivery method were identified as extreme Studentized residual values (PROC GLM, SAS Institute, Inc., Cary, N.C.). If an outlier could not be explained, it was removed to avoid violating assumptions of equal normality and variance. Deposition data were converted into volume of spray water and then $\log (x+1)$ transformed to stabilize the variance. The three subsamples associated with each spray replicate were then averaged, and the effects of delivery method and replicate were analyzed by analysis of variance (PROC GLM, SAS Institute, Inc., Cary, N.C.). Since two targets at two elevations were placed on three individual plants for each replicate, the SLICE option was also used to test for an interaction between delivery method and target elevation. The SLICE option specified the effects of delivery method and elevation by which to partition the LSMEANS. Means were separated using the least significant differences (LSD) procedure $(\alpha=0.05)$. Percent differences in canopy deposit data were $\log (x+1)$ transformed and analyzed using one-way ANOVA. Means were separated using the LSD procedure $(\alpha=0.05)$.

\section{Results AND DisCuSSION}

The atomization characteristics of the five treatments are shown in table 2 . The high-pressure $(3,583 \mathrm{kPa})$ Dramm Hydra treatment produced the smallest droplet sizes, while the low-pressure $(930 \mathrm{kPa})$ Dramm Hydra treatment produced the largest droplet sizes. The mean droplet velocity for the high-pressure Dramm Hydra treatment was significantly larger than the mean droplet velocity measured at the lowpressure operating condition. It was also observed that the high-pressure stream was able to more easily knock over potted plants than the low-pressure stream.

The air-assist nozzle treatment produced a wider droplet spectrum than the boom treatment using the TwinJet nozzles (table 2). This was expected since the flow out of each orifice of the TJ60-11002VS nozzles was approximately one-third 
Table 2. Spray equipment parameters.

\begin{tabular}{|c|c|c|c|c|c|c|}
\hline \multirow[b]{2}{*}{ Treatment } & \multirow{2}{*}{$\begin{array}{l}\text { Sizing Liquid } \\
\text { Pressure } \\
(\mathrm{kPa})\end{array}$} & \multirow{2}{*}{$\begin{array}{l}\text { Sampling } \\
\text { Distance } \\
(\mathrm{cm})\end{array}$} & \multicolumn{4}{|c|}{ Droplet Spectrum Characteristics } \\
\hline & & & $\begin{array}{l}D_{\mathrm{V} .10} \\
(\mu \mathrm{m})\end{array}$ & $\begin{array}{c}\mathrm{D}_{\mathrm{V} .50} \\
(\mu \mathrm{m})\end{array}$ & $\begin{array}{l}\mathrm{D}_{\mathrm{V} .90} \\
(\mu \mathrm{m})\end{array}$ & $\begin{array}{l}\text { Velocity } \\
\left(\mathrm{m} \mathrm{s}^{-1}\right)\end{array}$ \\
\hline Dramm Hydra (1.0) & 930 & $119 / 115^{[a]}$ & 115.8 & 281.9 & 576.1 & 6.07 \\
\hline Dramm Hydra (1.0) & 3,583 & $119 / 115^{[a]}$ & 64 & 128.9 & 214.4 & 12.56 \\
\hline TwinJet boom (TJ60-11002VS) & 930 & 50 & 118.7 & 152.9 & 200.1 & 3.42 \\
\hline Air-assist (XR11003) & 758 & 50 & 86.8 & 180.2 & 367.1 & 11.90 \\
\hline
\end{tabular}

[a] Hardware restrictions limited the maximum droplet size measurement distance from the nozzle to $119 \mathrm{~cm}$ and the maximum droplet velocity measurement distance to $115 \mathrm{~cm}$.

that of the flow out of the single-orifice XR11003 nozzles. Table 2 shows that the TwinJet nozzles produced the slowestmoving droplets in the region sampled.

Droplet velocity for the spray spectrum produced by the air-assist treatment was influenced by the air stream produced by the nozzle. The mean droplet velocity for the XR11003 nozzle without any form of air-assistance was $4.77 \mathrm{~m} \mathrm{~s}^{-1}$. The mean air velocities measured at the outlet and $35.6 \mathrm{~cm}$ below the outlet of the air-assist nozzle were 39.0 and $14.2 \mathrm{~m} \mathrm{~s}^{-1}$ respectively. Table 2 shows that with the aid of airassistance, mean droplet velocity $50 \mathrm{~cm}$ below the nozzle outlet was $11.90 \mathrm{~m} \mathrm{~s}^{-1}$ for the air-assist treatment.

The measured mean droplet velocity for the air-assist treatment at the $50 \mathrm{~cm}$ sampling distance was similar to the mean droplet velocity measured for the high-pressure Dramm Hydra treatment at the $115 \mathrm{~cm}$ sampling distance. The actual mean droplet velocity for the high-pressure Dramm Hydra treatment was likely lower in the target zone because it was actually more than double the distance from the nozzle as the sampling point for the static velocity measurements. In addition, the droplet velocity was likely lower from the spray stream of the Dramm Hydra treatment when it was being swept across the plant canopy compared to the static measurement reported in table 2.

Figure 6 shows a summary of the spray deposit on the artificial targets by elevation in the canopy and by treatment. Delivery method and replicate did not significantly $(\mathrm{p}>0.05)$ influence BSF deposition, but a nested two-way ANOVA identified a significant $(p<0.0001)$ effect when target position was nested within tracer delivery method (table 3 ). Least-squares means detected specific differences among spray deposit associated with delivery method and target elevation (fig. 6). Within each delivery method except the TwinJet boom at $935 \mathrm{~L} \mathrm{ha}^{-1}$, significantly $(\mathrm{p}<0.05)$ higher BSF deposition was detected on the upper canopy targets compared to the lower canopy targets (fig. 6). A marginally significant $(p=0.078)$ difference in BSF deposition occurred between the upper and lower targets for the boom at $935 \mathrm{~L}$ $\mathrm{ha}^{-1}$. However, within each target elevation (i.e., upper or lower elevation), significant differences were not detected $(p>0.05)$ across delivery methods in BSF deposition.

Overall, the high-pressure Hydra treatment $(3,583 \mathrm{kPa})$ produced the highest mean tracer deposit on the abaxial leaf surfaces in the upper elevation. However, the smaller and faster-moving droplets $\left(12.56 \mathrm{~m} \mathrm{~s}^{-1}\right)$ produced at high pressure did not penetrate and deposit on the abaxial leaf surfaces in the lower elevation any better than with the low-pressure Hydra treatments $\left(6.07 \mathrm{~m} \mathrm{~s}^{-1}\right)$. The air-assist treatment produced the highest mean deposit on the abaxial leaf surfaces in the lower canopy area. The greatest variability in tracer deposit was detected on the upper elevation targets associated with the Dramm Hydra at 3,583 $\mathrm{kPa}$ (fig. 6).

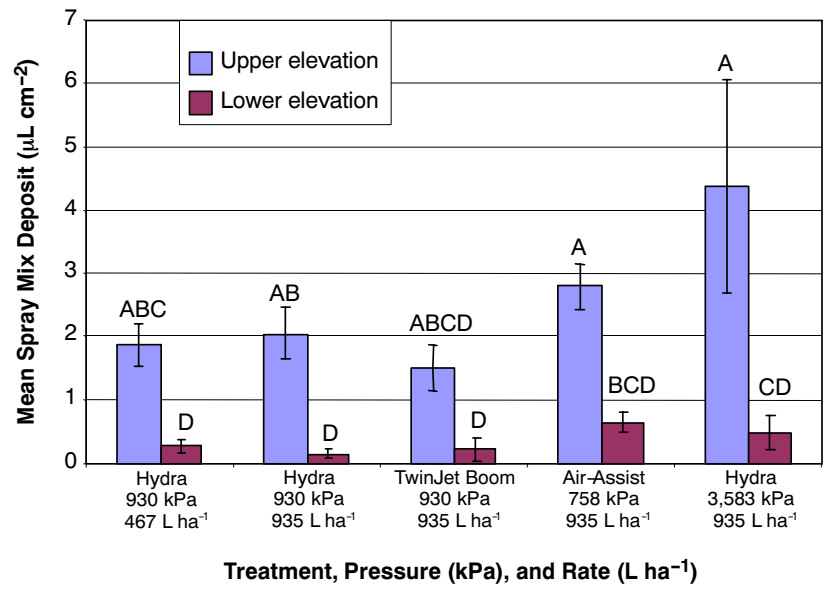

Figure 6. Mean spray volume deposits by treatment and canopy location and standard error bars for each location.

Table 3. Nested two-way ANOVA summary statistics for the influence of replicate, delivery method, and target position on BSF deposition.

\begin{tabular}{lccccc}
\hline Source & DF & $\begin{array}{c}\text { Type III } \\
\text { SS }\end{array}$ & $\begin{array}{c}\text { Mean } \\
\text { Square }\end{array}$ & $\begin{array}{c}\text { F } \\
\text { Value }\end{array}$ & Pr $>$ F \\
\hline Replicate & 4 & 0.07323022 & 0.01830756 & 0.78 & 0.5444 \\
Delivery method & 4 & 0.24205404 & 0.06051351 & 2.58 & 0.0533 \\
$\begin{array}{c}\text { Delivery method } \\
\quad \text { (position) }{ }^{[\mathrm{a}]}\end{array}$ & 5 & 1.91611418 & 0.38322284 & 16.37 & $<0.0001$
\end{tabular}

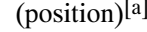

[a] Target position was considered a subgroup and therefore nested within delivery method for statistical analysis.

Spray volume was not a good predictor of abaxial leaf surface spray deposits in either the upper or lower canopy elevations. There were no significant differences in deposits between the handgun applications made at 467 and $935 \mathrm{~L}$ $\mathrm{ha}^{-1}$. Slowing the application to increase the overall application rate did not significantly improve abaxial surface deposition. These results for foliar deposits are similar to those reported by Derksen et al. (2008) for handgun applications made at different application rates. The lack of differences in abaxial leaf surface deposits at the two different application rates indicates that the pattern that the operator used in treating the bench of plants and the angle that the spray stream was directed at the canopy may have been more important than the spray volume.

There was a noticeable difference in the spray streams produced by the Dramm Hydra at 930 and 3,583 kPa. The higher pressure and volume spray stream consisted of smaller and faster-moving droplets (table 2). Mean deposits were higher for the high-pressure Dramm Hydra treatment $(3,583 \mathrm{kPa})$ on the abaxial surfaces of leaves in the upper elevation. Although not investigated here, the shallower trajectory of the Dramm Hydra spray stream $\left(30^{\circ}\right.$ below horizontal) 
compared to the TwinJet boom and air-assist treatments $\left(60^{\circ}\right.$ below horizontal) may have also contributed to higher abaxial surface deposition in the upper elevation. The highpressure treatment was directed across the canopy in a manner similar to the $435 \mathrm{~L} \mathrm{ha}^{-1}$ treatment. Abaxial leaf surface deposits in the lower canopy area were not significantly affected by the increase in pressure from 930 to $3,583 \mathrm{kPa}$. The high-pressure application, with its smaller and fastermoving droplets, did not provide any greater deposit on the abaxial surfaces of leaves in the lower elevation than the lowpressure treatments. The angle at which the Dramm Hydra spray stream was directed into the canopy could have reduced the effective canopy penetration and contributed to lower deposits deeper in the canopy.

The dual-spray stream attack of the TwinJet TJ60-11002VS nozzle produced the lowest mean deposit on the abaxial surfaces of leaves in the upper canopy area. The TwinJet boom treatment produced deposits similar to all of the other treatments on the abaxial surfaces of leaves in the lower canopy. These performance results are similar to those observed by Derksen et al. (2007) on bell pepper leaves, where the twin-fan nozzle produced coverage and deposition on leaves in the lower canopy similar to those of the other non-air-assist techniques. Derksen et al. (2008) reported that twin-fan, TwinJet nozzles failed to penetrate a dense and tall soybean canopy any better than other treatments and produced lower deposits on foliar tissue in the lower third of the canopy.

While Zhu et al. (2006) reported that the five-port, airassist nozzle produced good canopy penetration in small and narrow leaf taxus canopies, the abaxial leaf surface deposition produced by this nozzle on the relatively broad and flat poinsettia leaves was not significantly greater than that of the other treatments evaluated. The air delivery speed and the $30^{\circ}$ forward nozzle orientation did not produce significantly better abaxial leaf surface deposition on poinsettias compared to the other treatments.

Unlike broadcast sprayer treatments over the top of the canopy, the performance of the Hydra handgun significantly depends on how well the operator can target the canopy as the

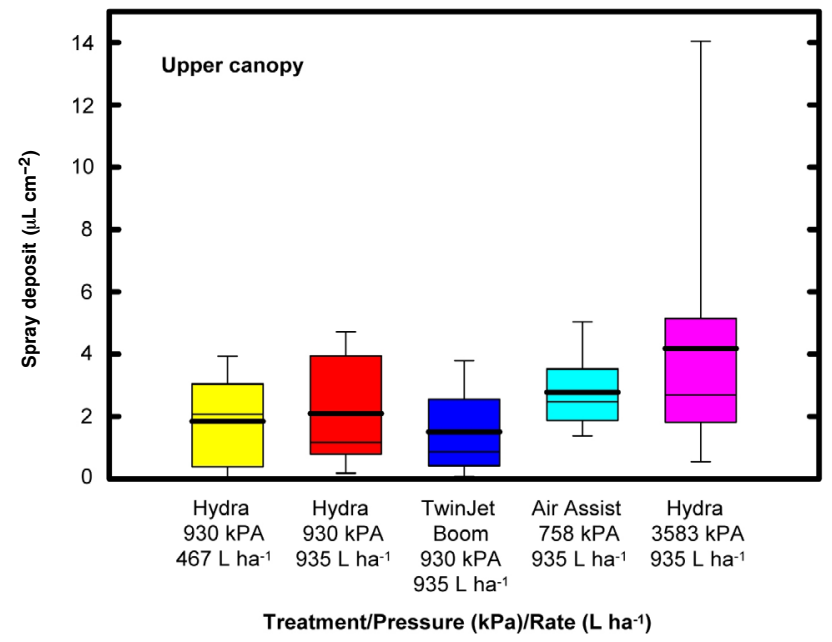

Figure 7. Box plots showing spray volume deposit on targets from the abaxial surfaces of leaves in the upper canopy from five types of sprayers. Boxes delineate 25 th and 75 th percentile values. The thin line inside each box represents the median, and the bold line represents the mean. The top and bottom lines around each box represent the 10th and 90th percentile values. spray stream is moved passed the plants. The box plots in figure 7 show the spread in the deposit measurements for each treatment. It is difficult to produce a uniform application with a handgun, and figure 7 shows that the high-pressure $(3,583 \mathrm{kPa})$ Hydra treatment produced the greatest spread of abaxial leaf surface deposits in the upper canopy area of the poinsettia canopy. The TwinJet boom and air-assist broadcast treatments produced the narrowest range in measurements.

The spread in abaxial leaf surface deposit data for the lower canopy area is represented in figure 8 . The high-pressure Hydra treatment also produced the greatest spread in deposits measured on the abaxial surfaces of leaves from the lower canopy. As can be seen in figure 8, the mean deposit is higher than the 75 th percentile value for the Hydra $3,583 \mathrm{kPa}$ treatment. There is also a wide spread in the deposit data for the TwinJet boom treatment, which was more likely the result of an inability to penetrate the canopy to that depth rather than the type of spray delivery pattern. The Hydra $935 \mathrm{kPa}$ and $935 \mathrm{~L} \mathrm{ha}^{-1}$ treatment produced the lowest spread in the lower canopy measurement but in general produced the lowest overall mean deposit.

The uniformity of spray deposits vertically through the poinsettia canopy is shown in table 4 . The vertical uniformity was characterized by calculating the percentage difference in the amount of spray deposit between the two sampling heights. For this analysis, one data point for the TwinJet boom treatment was excluded from the analysis because it was far outside the range observed for other data points from the same canopy location. Overall, numerically the air-assist treatment produced the least difference in the deposits between the two elevations (76.88\%). Statistically, there were no differences between the air-assist treatment and the highpressure Dramm Hydra and the low-pressure, low-volume Dramm Hydra treatments. There were no significant differences in the percent difference in canopy elevation deposits between any of the Dramm handgun treatments despite differences in spray volume and operating pressure. Numerically, the TwinJet boom treatment resulted in the greatest difference between the amounts of spray deposit found in the lower canopy compared to the upper canopy (97.29\%).

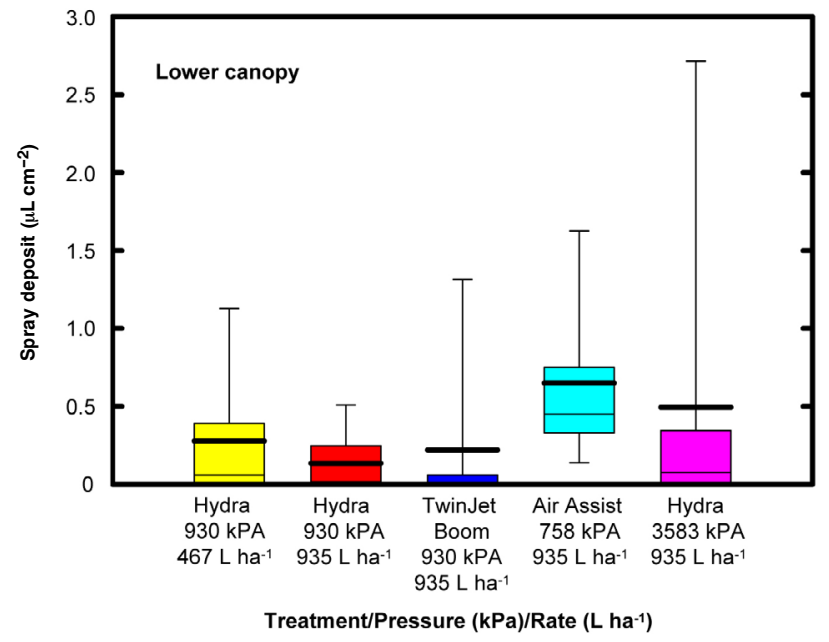

Figure 8. Box plots showing spray volume deposit on targets from the abaxial surfaces of leaves in the lower canopy from five types of sprayers. Boxes delineate 25 th and 75 th percentile values. The thin line inside each box represents the median, and the bold line represents the mean. The top and bottom lines around each box represent the 10th and 90th percentile values. 
Table 4. Comparison between upper and lower canopy spray deposition $(\mathrm{F}=2.34$; df = 4, 19; $p=0.0917)$.

\begin{tabular}{|c|c|c|c|c|}
\hline Treatment & $\begin{array}{l}\text { Spray Liquid } \\
\text { Pressure } \\
(\mathrm{kPa})\end{array}$ & $\begin{array}{c}\text { Application } \\
\text { Rate } \\
\left(\mathrm{L} \mathrm{ha}^{-1}\right)\end{array}$ & $\begin{array}{l}\text { Average Percent } \\
\text { Difference } \\
\text { in Deposits }\end{array}$ & $\begin{array}{c}\text { Standard } \\
\text { Error }\end{array}$ \\
\hline Dramm Hydra (1.0) & 930 & 467 & $85.06 \mathrm{ab}$ & 5.97 \\
\hline Dramm Hydra (1.0) & 930 & 934 & $92.72 \mathrm{~b}$ & 3.04 \\
\hline TwinJet boom (TJ60-11002VS) & 930 & 934 & $97.29 \mathrm{~b}$ & 1.36 \\
\hline Air-assist (XR11003) & 758 & 934 & $76.88 \mathrm{a}$ & 4.07 \\
\hline Dramm Hydra (1.0) & 3,583 & 934 & $84.62 \mathrm{ab}$ & 7.31 \\
\hline
\end{tabular}

\section{Summary ANd CONCluSions}

Managing ornamental pest problems on the abaxial surfaces of leaves is challenging, especially if treatment is limited to pesticides with a contact mode of action that do not readily move through plant tissue. Despite the relatively small distance between the upper and lower canopy sampling sites on the poinsettia plants in this study, significant differences in abaxial surface spray deposits were noted by elevation for most treatments. Statistically, there were no significant differences between treatments at either canopy elevation. Greater variability in mean spray deposits were noted at the upper canopy elevation compared to the lower canopy elevation. Overall, spray volume, as changed by application speed of the handgun treatment, did not significantly affect spray deposit at either canopy location. While increasing operating pressure by a factor of 4 significantly changed the atomization characteristics and droplet velocity of the handgun spray stream and resulted in higher mean deposits in the upper canopy, they were not significantly greater than the mean deposits of the lower-pressure handgun treatments. Higher operating pressure also did not improve canopy penetration or spray deposits on abaxial surfaces. While air-assistance with a flat-fan nozzle inclined at $30^{\circ}$ increased mean deposits over a non-air-assist boom treatment, the results were not significantly different. Air-assistance produced the least difference in the variability between deposits measured at two different elevations in the canopy.

Overall, variability of results within some of the treatments was quite high. Variability could be important in terms of ensuring uniform results, especially if contact materials are being applied or if injury to sensitive ornamental plants could result from overapplication. While all handgun applications produced high variability in the results, the highpressure handgun treatment produced the greatest variability across target plants. Broadcast applications with the TwinJet boom nozzles and the air-assist treatment produced lower variability in spray deposits. Ultimately, distribution of spray with a handgun will be influenced by the skill of the operator. Producers will benefit from means to achieve more uniform applications and apply more predictable amounts of treatments in the target area, especially when handguns are used to apply treatments. Further research is needed to help identify how to improve uniformity and to determine the impact of spray quality on biological efficacy.

\section{ACKNOWLEDGEMENTS}

The authors thank the Raker \& Sons for donating the rooted cuttings used in this study. The authors also appreciate the help of Andy Doklovic and Dan Troyer in preparing the equipment for the field trial; the help of Leslie Morris, Tony Karcher, Adam Clark, James Moyseenko, Ann Widrig, and Doug Sturtz for collecting field samples and analyzing spray retention; and Barry Nudd for measuring spray spectrum characteristics of all atomizers.

\section{REFERENCES}

Derksen, R. C., and J. P. Sanderson. 1996. Volume, speed, and distribution technique effects on poinsettia foliar deposits. Trans. ASAE 39(1): 5-9.

Derksen, R. C., S. A. Miller, H. E. Ozkan, and R. D. Fox. 2001. Spray deposition characteristics on tomatoes and disease management as influenced by droplet size, spray volume, and air-assistance. ASAE Paper No. 011120. St. Joseph, Mich.: ASAE.

Derksen, R. C., S. Vitanza, C. Welty, S. Miller, M. Bennett., and H. Zhu. 2007. Field evaluation of application variables and plant spacing for bell pepper pest management. Trans. ASABE 50(6): 1945-1953.

Derksen, R. C., J. Frantz, C. M. Ranger, J. C. Locke, H. Zhu, and C. R. Krause. 2008. Comparing greenhouse handgun delivery to poinsettias by spray volume and quality. Trans. ASABE 51(1): 27-33.

Ebert, T. A., R. C. Derksen, R. A. Downer, and C. R. Krause. 2003. Comparing greenhouse sprayers: The dose-transfer process. Pest Mgmt. Sci. 60(5): 507-513.

Fox, R. D., R. C. Derksen, H. Zhu, R. A. Downer, and R. D. Brazee. 2004. Airborne spray collection efficiency of nylon screens. Applied Eng. in Agric. 20(2): 147-152.

Güler, H., H. Zhu, H. E. Ozkan, R. C. Derksen, Y. Yu, and C. R. Krause. 2007. Spray characteristics and drift reduction potential with air induction and conventional flat-fan nozzles. Trans. $A S A B E$ 50(3): 745-754.

Knewitz, H., H. Koch, and F. Lehn. 2003. Einsatz eines Düsenverbandes und flächenbezogene Dosierung bei der Anwendung von Pflanzenschutzmitteln im Gewächshaus. Gesunde Pflanzen 55(3): 70-76.

Langenakens, J., G. Vergauwe, and A. De Moor. 2002. Comparing handheld spray guns and spray booms in lettuce crops in a greenhouse. Aspects of Applied Biology 66: 123-128. Warwick, U.K.: Association of Applied Biologists.

May, M. J. 1991. Early studies on spray drift deposition, and weed control in sugarbeet with two air-assisted boom sprayers. In Air-Assisted Spraying in Crop Protection, 89-97. A. Lavers, P. Herrington, and E. S. E. Southcombe, eds. BCPC Monograph No. 46. Farnham, U.K.: British Crop Protection Council.

Mueller, D. S., A. E. Dorrance, R. C. Derksen, E. Ozkan, J. E. Kurle, C. R. Grau, J. M. Gaska, G. L. Hartman, C. A. Bradley, and W. L. Pedersen. 2002. Efficacy of fungicides on Sclerotinia sclerotiorum and their potential for control of Sclerotinia stem rot soybean. Plant Disease 86(1): 26-31

Nuyttens, D., S. Windey, and B. Sonck. 2004. Optimisation of a vertical spray boom for greenhouse spray applications. Biosystems Eng. 89(4): 417-423.

Ozkan, H. E., H. Zhu, R. C. Derksen, H. Güler, and C. R. Krause. 2006. Evaluation of various spraying equipment for effective application of fungicides to control Asian soybean rust. Aspects of Applied Biology 77: 423-431. Warwick, U.K.: Association of Applied Biologists. 
Piché, M., B. Panneton, and R. Thériault. 2000. Field evaluation of air-assisted boom spraying on broccoli and potato. Trans. ASAE 43(4): 793-799.

USDA. 2008. Floriculture and Nursery Crops Yearbook. FLO-2007. Washington, D.C.: USDA Economic Research Service, Market and Trade Economics Division.

Womac, A. R., J. E. Mulrooney, and W. P. Scott. 1992. Characteristics of air-assisted and drop-nozzle sprays in cotton. Trans. ASAE 35(5): 1369-1376.
Zhu, H., D. L. Rowland, J. W. Dorner, R. C. Derksen, and R. B. Sorensen. 2002. Influence of plant structure, orifice size, and nozzle inclination on spray penetration into peanut canopy. Trans. ASAE 45(5): 1285-1301.

Zhu, H., J. W. Dorner, D. L. Rowland, R. C. Derksen, and H. E. Ozkan. 2004. Spray penetration into peanut canopies with hydraulic nozzle tips. Biosystems Eng. 87(3): 275-283.

Zhu H., R. D. Brazee, R. C. Derksen, R. D. Fox, C. R. Krause, H. E. Ozkan, and K. Losely. 2006. A specially designed air-assisted sprayer to improve spray penetration and air jet velocity distribution inside dense nursery crops. Trans. ASABE 49(5): 1285-1294. 